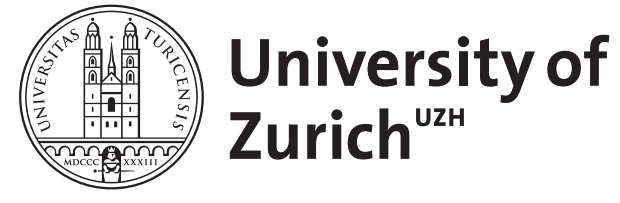

Zurich Open Repository and Archive

University of Zurich

Main Library

Strickhofstrasse 39

CH-8057 Zurich

www.zora.uzh.ch

Year: 2012

\title{
Pragmatics in the history of linguistic thought
}

Jucker, Andreas H

Posted at the Zurich Open Repository and Archive, University of Zurich

ZORA URL: https://doi.org/10.5167/uzh-57900

Book Section

Published Version

Originally published at:

Jucker, Andreas H (2012). Pragmatics in the history of linguistic thought. In: Allan, Keith; Jaszczolt, Kasia M. The Cambridge Handbook of Pragmatics. Cambridge: Cambridge University Press, 495-512. 


\title{
Pragmatics in the history of linguistic thought
}

\author{
Andreas H. Jucker
}

\subsection{Introduction}

Pragmatics is still a relatively young branch of linguistics. It was only in the early 1970 s that more and more linguists started to devote their attention to this field. The International Pragmatics Association (IPrA) was founded in 1985. Its early conferences took place in Viareggio (1985), Antwerp (1987). Barcelona (1990), and Kobe, Japan (1993). The international Journal of Pragmatics started publication in 1977, and the journal Pragmatics in 1991 (Mey 1998b: 720). The Journal of Pragmatics started with about 400 pages per year in the seventies and has steadily increased its volume to over 2,500 pages per year by 2009. This increase is mirrored in similar increases in the volume of textbooks, monographs, collected volumes, more specialized journals (Pragmatics \& Cognition 1993, Historical Pragmatics 2000, Intercultural Pragmatic 2004, International Review of Pragmatics 2009, Pragmatics and Society 2010), and in particular in the publication of handbooks in pragmatics (Mey 1998b; Verschueren et al. 2003; Horn and Ward 2004; Mey 2009a; Cummings 2010; and Bublitz et al. 2010-). Pragmatics is no longer just a small subfield of linguistics but one of the dominant areas, indeed it may be argued to have become a discipline in its own right. It has developed "from a humble beginning at the remote outposts of philosophy and linguistic semantics... into a vast realm where often conflicting theories and practices reign" (Mey 2009a: vi).

Given such a large and diverse field of study, it might reasonably be questioned whether it is at all possible to write a coherent history for this field. In 1996, Biletzki still maintained that this was not possible. Pragmatics according to him - did not have a history.

Its maturity is attested to by both the number of practitioners in the field, and the variety of directions in which its branches grow out to various 
disciplines. Yet sitting on any of the branches of this pragmatic tree be they philosophical, linguistic, psychological - one wonders if the tr mightn't topple over for lack of roots. For pragmatics seems to have no formal, institutionalized history. (Biletzki 1996: 455)

In the meantime, several (partial) histories of pragmatics have appeared most notably Nerlich and Clarke (1996) and Nerlich $(2009,2010)$

Two issues are at stake. First, where does the history begin and period does it cover? Does it focus exclusively on the roots of the disciplin before it constituted itself as a recognized field of study? Or does it alsipline the development of the discipline over the forty or so years of its existence? The introduction of the term "pragmatics" is generally attributed to Charle Sanders Peirce (1839-1914) and to Charles Morris (1901-1979), but the field only constituted itself as such in the 1970s. And second, the but theld pragmatics must decide on the delimita order to locate its various roots at a time field of pragmatics in when the field had not constituted

I shall take a broad view on both these issues by including not only prag the development of the disciplne account of co discipline itself and by adopting a broad, basically Continental European view of pragmatics (see below). First, I shall briefly outline some of the roots of pragmatics in the academic traditions of the nineteenth and early twentieth century, at a time when the term "pragmat ics" had not been introduced and when it was not linguists but scholars in other fields who were interested in studying the use of language. In a second step I shall briefly refer to the work by philosophers such as Peirce, Morris, and Carnap, who in the first half of the twentieth century first introduced and used the term "pragmatics". This leads on to the work by the ordinary language philosophers Austin and Searle, and also to Grice, who in the 1950 and 1960 s to a large extent set the agenda for the more widespread work in pragmatics in the 1970 s and 1980 s, when the field of pragmatics really took off and was taken over by linguists. The second part of this contribution is then devoted to the further development of pragmatics in the context of linguistic thought in general and against the background of some important paradigm shifts that have radically transformed the landscape of linguistics over the last four or five decades.

\subsection{Pragmatics avant la lettre}

In a wider sense the roots of pragmatics can be located in all those philo sophical traditions that rejected the "descriptive fallacy" (Austin 1962: 3), i.e. the idea that language represents states of affairs that are either true or false. Language is more than just a representation of thoughts, it is used by speakers to communicate with each other, to influence hearers in certain ways, and, indeed, to change the world (see Nerlich 2010: 193). Such a rew of language has its roots in antiquity. It was part of the rhetoric in the tiberal arts" or "trivium" of rhetoric, grammar, and logic. From its earliest beginnings rhetoric has been concerned with the art of persuasion, with the different methods by which speakers can influence their audience. In his Rhetoric Aristotle distinguished three ways of persuading others: logos, the appeal to their reason; pathos, the appeal to their emotions; and ethos, the appeal to the speaker's personality or character (see Corbett 1990: 37). Aristotle thus focuses on the effect that language has on the audience and how these effects can be achieved (see Dascal and Gross 1999; Tindale 2010). ${ }^{1}$

In the nineteenth century language studies were almost exclusively focused on historical-comparative linguistics, the regularities of sound change, and the reconstruction of earlier languages. Linguists were interested in individual languages and the relationships between them. They compared different languages in order to establish common ancestor languages and in order to reconstruct older languages. Such a perspective did not leave much room for studying language in use, language in its social and communicative context, and the effects of language on the audience. However, there were several neighboring disciplines such as philosophy, psychology, sociology, and semiotics, in which language was seen from an interactive and communicative perspective. What these disciplines had in common was that they saw language not just as an organism growing in more or less predictable ways and not as a system that only serves to represent true or false states of affairs, but as a means to communicate with others, as a means of influencing others in specific ways, and as a means of doing things (see Nerlich 2009: 329; Nerlich and Clarke 1996).

\subsection{Early uses of the term "pragmatics"}

It is the American mathematician and philosopher Charles S. Peirce (18391914) who is generally credited with the coining of the term "pragmatism." Parmentier (1997:3), however, points out that it was the psychologist William James (1842-1910) who introduced it as the "principle of Peirce" into philosophical discourse. But Peirce is the father of pragmatism, a theory of meaning that is based on a theory of signs and the effects which they have on our conduct (see Nöth 1990: 41). The theory also focuses on the connection between thought and action. Later, Peirce changed the term "pragmatism" to "pragmaticism" in order to differentiate it from James's use of the term, taking "pragmaticism" to be a term "so ugly that... no one would dare steal it" (Parmentier 1997: 5).

The American philosopher Charles Morris (1901-1979) integrated ideas from Peirce's pragmatism or pragmaticism into his own theory of signs, which he called "semiotic," using a term coined by John Locke (1632-1704). 
Today the field is commonly known as "semiotics." The most famous aspec of this theory for linguists and pragmaticists is the semiotic triangle. Morris distinguished three branches of semiotics: syntactics, semantics, and pras matics, which are devoted to the syntactical, semantical, and pragmatica aspects of signs. Syntactics deals with signs and their relationships toward each other. Semantics deals with the signs and their meanings. And prag matics deals with the signs in relation to their users. In fact, every sign must always include all three dimensions of semiosis. It is only for ana lytical purposes that the relation between different signs, the meaning of signs, and the relation of signs to their users can be distinguished (se Petrilli 2000: 6 for details). Morris's conceptualization of pragmatics wa very broad. "It is a sufficiently accurate characterization of pragmatics to say that it deals with the biotic aspects of semiosis, that is, with all the psychological, biological, and sociological phenomena which occur in the functioning of signs" (Morris 1938: 108; quoted by Levinson 1983: 2). Such definition is much broader than the Anglo-American approach to pragmat ics and is much closer to the Continental European approach (see below section 24.5).

The German-born and U.S.-naturalized philosopher Rudolf Carnap (1891 1970), on the other hand, was influential in narrowing down the scope of pragmatics. He conceptualized Morris's semiotic triangle in the following way.

If in an investigation explicit reference is made to the speaker, or to put it in more general terms, to the user of the language, then we assign it [the investigation] to the field of pragmatics ... If we abstract from the user of the language and analyze only the expressions and their designata, we ar in the field of semantics. And, finally, if we abstract from the designata also and analyze only the relations between the expressions, we are in (Iogical) syntax. (Carnap 1938; quoted by Levinson 1983: 2-3)

This definition of pragmatics focuses on the user of the language. It does not invoke the effects on the audience or the larger social and cultural contex in which language is used.

Levinson (1983: 3) points out that Carnap's definition of pragmatics led some scholars to adopt a very restricted scope of pragmatics, which was basically reduced to considerations of deictic elements. Elements, such as I you, this, here, and so on, require for their interpretation reference to the user of these expressions and, therefore, fall squarely under Carnap's definition for whom the domain of semantics is a proper part of that of pragmatics opposite to current contextualism.

But at the same time philosophers like Austin, Searle, and Grice had already started to analyze ordinary language. They came to be known as "ordinary language philosophers," had a massive influence on the early development of pragmatics - and they continue to be influential up to the present day.

\subsection{Philosophers of language}

Betrand Russell (1872-1970) and Ludwig Wittgenstein (1889-1951) in his early writings (often called the Early Wittgenstein) advocated a form of analytical philosophy that relied on an ideal language and on symbolic logic or quasi-mathematical notation for the analysis of philosophical problems. The ordinary-language philosophers, on the other hand, focused their attention on an analysis of ordinary rather than ideal languages. It was, in fact, Ludwig Wittgenstein in his later writings (known as the Later Wittgenstein), who was one of the earliest proponents of ordinary-language philosophy. It is still a matter of controversy how exactly the Later Wittgenstein differs from the Early Wittgenstein, but it is the Later Wittgenstein's views on the meaning of words that are particularly important for the development of pragmatics. He refutes the position that words in a language name objects and that sentences are combinations of such names. Instead, Wittgenstein proposes that the meaning of a word in a large class of cases is "its use in the language" (Wittgenstein 1953: 18).

The Oxford philosopher J. L. Austin (1911-1960) is best known for his posthumously published book How to Do Things With Words (1962). The book was based on the lecture notes of the William James Lectures he delivered at Harvard University in 1955 . The book starts with the contrast between performative utterances, i.e. utterances that perform an action, and assertions or constatives that describe a state of affairs and have specific truth conditions. Performatives do not have truth conditions; instead they have felicity conditions, that is to say conditions which must be satisfied in order for the speech act to successfully perform the intended action. In the later part of the book, the theory is extended into a more comprehensive account in which constatives, too, are seen as actions. By using them, speakers perform the action of stating and thus these acts are also subject to felicity conditions (Austin 1962: 136). In his discussion of speech acts, Austin distinguishes three main aspects that pertain to every speech act. The first aspect, the so-called locutionary act, consists in the act of uttering speech sounds, the basic act of talking itself. The second aspect, the illocutionary act of an utterance, describes the conventional nature of an act, such as stating, ordering, asking, promising, warning, or thanking. The third aspect, finally, the perlocutionary act, describes the effect that is achieved by performing the act, for instance in the form of persuading or convincing the addressee or getting him or her to do something (see Sbisà 2006, 2010; also Kissine, this volume).

Austin's theory of speech acts is often conflated with that of John Searle (b. 1932), who has been described as "one of the most influential contributors to speech act theory and pragmatics in the last forty years" (Kirk 2010: 416). Searle studied at Oxford with Peter Strawson, Peter Geach, and J. L. Austin. After his studies he took up a position at the University of California at 
Berkeley. On the basis of Austin's pioneering framework Searle developed a more thorough and more detailed theory for the analysis of speech oped In his consideration of illocutionary acts, to pick out a central aspect acts theory, he explicates a set of conditions that must obtain for the succ of performance of particular illocutionary acts, and on that for the successful the constitutive rules for that particular speech act He demsis hells out steps with the example of promising (Searlech act. He demonstrates these content rule specifies that the proposition (Searle 1969: 57-64). The propositiona act $A$ of the speaker $S$. The preparatory rule a promise must concern a future be successfully uttered if $S$ has good rule specifies that a promise can only $S$ 's doing $A$ to his or her hot good reasons to believe that $H$ would prefer $S$ and $H$ that $S$ will do $A$ anyway. The and only if it is not obvious to both $S$ and $H$ that $S$ will do A anyway. The sincerity rule states that a promise finally, requires that the essential rule, an obligation to do A. utterance in question counts as an undertaking of
and

The third philosopher of language who had a major and lasting influence on pragmatics was H. Paul Grice (1913-1988). In pragmatics he is best known for his theory of cooperation and conversational implicatures, which is basically an account of how a hearer can work out aspects of meaning that a speaker intended without explicitly expressing them. ${ }^{2}$ He starts by noting that conversations are - generally speaking - cooperative enterprises, which he formulated in his "Cooperative Principle": "Make your conversational con tribution such as is required, at the stage at which it occurs, by the accepted purpose or direction of the talk exchange in which you are engaged" (Grice 1975: 45). At a more detailed level and echoing Kant, Grice distinguishes the four categories of Quantity, Quality, Relation, and Manner, and within thes categories a number of more detailed maxims. The category of Quantity has to do with the quantity of information provided and its two maxims state that speakers should make their contributions as informative as is required and they should not make them more informative than is required. The category of Quality has one supermaxim that stipulates that speakers try to make their contribution one that is true, with the more specific maxims not to say what they believe to be false and not to say that for which they nock adequate evidence. The category of Relation contains a single maxim "Be relevant." The category of Manner, finally, relates not to what is said but to how it is said. The supermaxim requires the speaker to be perspicuous, and the specific maxims spell this out by requiring the speaker to avoid obscurity of expression and ambiguity, and to be brief and orderly.

Interlocutors generally assume each other to be cooperative, but speakers may fail to observe one of the maxims. In some cases the requirements of two maxims clash, as for instance, when a speaker cannot give as much information as is required without violating the maxim of truthfulness. The assumption that speakers are generally cooperative even if on occasions they fail to observe all of the maxims provides a systematic account of how hearers can read between the lines of what the speaker says, that is to say how they can work out the implicit meaning or - in Grice's words - the "conversational implicatures" (Grice 1975: 49). Such implicatures may result when the maxims are observed. When a speaker asserts that "most students have handed in their assignments," he or she implicates that some did not because otherwise it would have been more informative to say "all students." Implicatures also derive if maxims are flouted, i.e. if their requirements are not fulfilled in order to achieve a particular effect. In the case of irony, for instance, the maxim of truthfulness is flouted in order to communicate a related proposition. If a speaker says " $X$ is a fine friend," to use Grice's (1975: 53) example, in a situation in which it is clear to the speaker and the hearer that the speaker does not believe this, an implicature derives that states by and large the opposite of what the proposition expresses.

Grice's work, like that of Austin and Searle, has had a lasting influence on the development of pragmatics. It is the work of these three philosophers that has most regularly been referred to in all the textbooks on pragmatics, from the very early ones, e.g. Leech (1983) and Levinson (1983), to the more recent, e.g. Cummings (2005), Huang (2007), and Bublitz (2009).

\subsection{Anglo-American and Continental European pragmatics}

Quite early in the history of pragmatics two different ways of doing pragmatics, or schools of thought as Huang (2007: 4-5; 2010: 341) calls them, established themselves. One of these ways can conveniently be described as the Anglo-American tradition of pragmatics, the other as the Continental European tradition. Levinson (1983: 2, 5-6) had already pointed out the distinction between these two traditions, and it is noteworthy that thirty years later the two traditions can still be clearly delimited in the various textbooks and handbooks. Cruse's (2000: 16) definition of pragmatics is typical for the Anglo-American school of thought:

[P]ragmatics can be taken to be concerned with aspects of information (in the widest sense) conveyed through language which (a) are not encoded by generally accepted convention in the linguistic forms used, but which (b) none the less arise naturally out of and depend on the meanings conventionally encoded in the linguistic forms used, taken in conjunction with the context in which the forms are used.

Thus, within this school of thought, pragmatics is concerned with the study of meaning that arises through the use of language. This is also called the component view of pragmatics. Pragmatics is seen as one of the core components within linguistics responsible for a clearly delimited set of tasks and clearly distinct from other core components, such as semantics, syntax, morphology, or phonology. On this view, anthropological linguistics, 

applied linguistics, and psycholinguistics are considered to be more periph
eral components of linguistics (Huang 2007:4). The set of tasks for which a component is responsible includes the study of presuppositions, duch implicatures, and speech acts.

The Continental European school of thought, on the other hand pragmatics to have a much wider range of tasks. In fact, it is not seen as particular component of linguistics on a par with other components, as a specific perspective for studying language in general. Verschueren (1999:
1) provides a typical definition:

[P]ragmatics can be defined as the study of language use, or, to employ a somewhat more complicated phrasing, the study of linguistic phenomena from the point of view of their usage properties and processes. [Sic.]

He adds explicitly that "pragmatics does not constitute an additional compo. nent of a theory of language, but it offers a different perspective" (Verschueren 1999: 2, italics original). This school of thought, therefore, is also called the perspective view. Mey (2001: 6) proposes an equally wide view of pragmatics:

Communication in society happens chiefly by means of language. How. ever, the users of language, as social beings, communicate and use lan. guage on society's premises; society controls their access to linguistic and communicative means. Pragmatics, as the study of the way humans use their language in communication, bases itself on a study of those premise and determines how they affect, and effectualize, human language use Hence: Pragmatics studies the use of language in human communication as deter. mined by the conditions of society. [Sic.]

Mey's textbook is split into two parts, entitled "micropragmatics" and "macropragmatics." Micropragmatics deals with context, implicature, refer ence, pragmatic principles, speech acts, and conversation analysis and thus coincides more or less with the research interests of Anglo-American prag matics, while the part entitled macropragmatics adds a range of topics that are only part of Continental European but not Anglo-American pragmatics, such as literary pragmatics, intercultural pragmatics, and the social aspects of pragmatics.

The difference between these two schools of thought is clearly reflected in the relevant textbooks and handbooks of pragmatics. Horn and Ward (2004), for instance, explicitly exclude the broader, sociologically based European view of pragmatics from their Handbook of Pragmatics and focus on the "more narrowly circumscribed, mainly Anglo-American conception of linguistic and philosophical pragmatics and its applications" (Horn and Ward 2004: xi). Huang (2007: 5), who also adopts an Anglo-American approach in his textbook on pragmatics, argues that the Continental European tradition is too all-inclusive and therefore lacks a clear delimitation and tradition attempt to establish a coherent research agenda.
The textbooks by Verschueren (1999) and Mey (2001) mentioned above dearly adopt the wider Continental European approach and also include questions about the social and cultural contexts in which language is used. The Handbook of Pragmatics edited by Verschueren et al. (2003) and the series of handbooks edited by Bublitz et al. (2010-) also include many topics that consider the use of language from a cultural and social perspective.

\subsection{Paradigm shifts and diversification of pragmatics}

The beginning of pragmatics as an independent subdiscipline within linguistics constituted a major paradigm shift in linguistics. To repeat, it took place in the 1970s and 1980s and radically changed the landscape of linguistics. "What was marginal in the 1970s has come to be of central interest above all pragmatics" (Traugott 2008b: 207). It was accompanied and followed by several smaller paradigm shifts. Together they brought with them an unprecedented strengthening and broadening of the field of pragmatics, but they also led to a significant diversification of pragmatics and a split into many subdisciplines of pragmatics. Particularly important in this respect are the following paradigm shifts (based in part on a much longer list in Traugott 2008b: 208-9).

1) From competence to the use of language. Speakers do not just rely on one homogeneous system of language use. They adopt their use of language to the changing situations in which they find themselves in the course of their daily lives.

2) From introspective data to empirical investigations of contextualized data of very different kinds. Such data includes both spoken and written instantiations of language ranging from formal to informal, from polite to hostile and aggressive, from casual to academic, and so on.

3) From homogeneity to heterogeneity. Language is no longer seen as a homogeneous but as a dynamic system subject to spatial, social, and diachronic variation.

4) From synchrony to diachrony. Language change is seen as an important factor in the description of language and of languages.

These paradigm shifts individually and in combination affected the development not only of linguistics but also of pragmatics. In the following sections, I shall briefly sketch their significance for the current state of research in pragmatics.

\subsubsection{From competence to the use of language}

The paradigm shift from an analysis of native speaker competence to the study of the use of language affected linguistics as a whole. It is often called "the pragmatic turn" and as such is the foundation stone of pragmatics in general. Before this shift, there were only few linguists who were interested 
in the use of language. But the shift brought a sea change. Pragmatics becan mainstream.

The Chomskyan school of linguistics, which dominated the discipline in the 1960s and 1970s saw a theory of syntax as the main theoretical framewor and tried to integrate the other levels of linguistic descriptions - phonology morphology, and semantics - into this framework. Linguistic theory, accor ing to Chomsky (1965:9), was concerned with "the knowledge of the Iang by a speaker-hearer," i.e. the language competence of the speaker and the hearer. He explicitly excluded the study of how language was used in actur situations, i.e. the study of performance.

John Robert Ross and George Lakoff were the first linguists who tried to fre themselves from the domination of syntax. Lakoff proposed an alternative framework called "generative semantics", in which semantics rather than syntax was the driving force. But later Ross and Lakoff started to work what came to be known as pragmatic territory.

The American structuralists had treated language with a scientific rigo borrowed from the natural sciences. Meaning had not played a significant role in such an endeavor. Chomsky allowed such semantic notions as syn onymy and ambiguity into his theory and thus "opened a door for semantics" (Leech 1983: 2). Ross and Lakoff opened the door even further. Generative semantics, however, which in spite of its name was still mainly a syntactic theory rather than a semantic one, was short-lived. It turned out that some of the problems, such as presuppositions and illocutionary force, could not really be handled in such a framework.

Forty years ago in a paper aptly entitled "Out of the pragmatic wastebas ket", the Israeli linguist Yehoshua Bar-Hillel (1915-1975) complained about scholars who ignored the pragmatic nature of certain linguistic problems and tried to force them into syntactic or semantic theories. "Be more careful with forcing bits and pieces you find in the pragmatic wastebasket into your favorite syntactico-semantic theory" (Bar-Hillel 1971: 405). His image of the "pragmatic wastebasket" has often been quoted to refer to problems that resisted a satisfactory analysis at the level of syntax or semantics.

In the end, the wastebasket started to overflow and many linguists started to turn their interests to the contents of the wastebasket itself.

When linguistic pioneers such as Ross and Lakoff staked a claim in prag. matics in the late 1960 s, they encountered there an indigenous breed of philosophers of language who had been quietly cultivating the territory for some time. In fact, the more lasting influences on modern pragmatics have been those of philosophers; notably, in recent years, Austin (1962), Searle (1969), and Grice (1975). (Leech 1983:2)

As a result, the early work by linguists who turned their attention to the "performance" of language, i.e. the use of language in context, could fall back on the work by these language philosophers. As pointed out in the opening paragraph of this paper, pragmatics constituted itself as a significant subfield of linguistics in the late 1970s and early 1980 s with its own journal (Journal of Pragmatics) that started publication in 1977, with its ories of international conferences in the 1980 s and with several relevant a series of (Levinson 1983; Leech 1983; and Green, G. M. 1989; but see also the very influential monograph by Gazdar 1979). The language problems that treviously had been assigned to the wastebasket had become respectable and previously had been assigned to the wastebasket had of onger on the competence of the native speaker-hearer but on the performance in actual situations. In Mey's (2009a: 796) words,

[the waste basket has served its function - I am not saying it is quite empty yet, but we have managed to upgrade the basket to a more prominent position, and accorded it descriptive and explanatory status as a recognized field of language studies.

\subsubsection{From introspective data to empirical investigations}

The language philosophers Austin, Searle, and Grice had all worked with introspective data. Their reflections on language were based on their intuition and their competence as native speakers of English. In linguistics, dominated by Chomskyan linguistics, too, introspection was the only - and the only acceptable - method of research. The object of study was the internalized language (i-language for short) of the native speaker, i.e. the system of knowledge that underlies the native speaker's ability to use and understand language, rather than the externalized language (or e-language), which manifests itself in observable reality (see Chomsky 1986:19-24). The only access to i-language was through the native speaker's intuition. Intuition was deemed to be superior to corpus data because corpus data, even if extremely large, may fail to contain a particular construction that any native speaker immediately recognizes as grammatical.

One major branch of linguistics that broke away from this tradition was sociolinguistics, which turned to rigorously empirical methods in order to investigate how actual language use (forms of e-language in Chomsky's terms) correlates with the social class of its speakers (see, for instance, Labov 1972). Many pragmaticists, too, soon started to employ empirical methods of language investigation. In 1974 a paper appeared in Language, which had a lasting influence on pragmatics. In it, Sacks, Schegloff, and Jefferson, three sociologists and ethnomethodologists, used detailed transcriptions of naturally occurring conversations in order to analyze the minutiae of the turn-taking system. In the 1980 s, conversation analysis and discourse analysis became important branches within linguistics. Not all of them took their analytical methods from Sacks et al. (1974), but they all relied on faithfully transcribed data from more or less naturally occurring conversations and on detailed analyses of the regularities in this type of data. Landmark publications were, for instance, Schiffrin's (1987) seminal analysis of discourse markers or the textbooks by G. Brown and Yule (1983) or Stubbs (1983). 
In the 1980 s pragmaticists also began to experiment more systematically with elicitation techniques. Blum-Kulka et al. (1989), for instance, used discourse completion tasks in order to investigate differences in the ways in which different cultures issue requests or apologies. Requests and apologies: are two speech acts that are particularly interesting for such an investiga. tion since requests threaten the addressee's negative face and apologies the speaker's own positive face in the sense of P. Brown and Levinson (1987). In such tasks, an utterance by an interlocutor would be given. This can be a university lecturer, for instance, who reminds the student respondent of a book that should have been returned by today. The respondent's answer is left open for the participant to fill in. A second utterance by the lecturer then indicates that the apology has been accepted. Discourse completion tasks, in spite of the criticism that they have subsequently received, are a useful means for gathering large amounts of data that is comparable across different groups of speakers, and it is a method that is still regularly used by some pragmaticists.

Trosborg (1995) also investigated requests and apologies, to which she added complaints as speech acts that threaten the addressee's positive face. She used role plays and role enactments as a method to elicit these speech acts from Danish learners of English and from native speakers of English. In a role play, the participants impersonate a personality that differs from their own experience, while in a role enactment they perform a role that is part of their normal life or personality. The participants would be asked, for instance, to perform the role of a student who complains to a fellow student living in a flat upstairs about the noise that is preventing him or her from preparing a talk for the next day.

In the 1990 s the computer became more and more important as a research tool in linguistics in general. By that time, corpus linguistics had already established itself as a respectable field of linguistic enquiry, but the nineties, with the more widespread availability of computers and personal computers in particular, led to an explosion of computer corpora and of corpus-based work in linguistics. It took somewhat longer for this trend to reach pragmatics. A pioneering example is the work by Aijmer, who used the London-Lund Corpus of Spoken English to describe conversational routines, such as thanking, apologizing, and making requests (Aijmer 1996), and discourse particles, such as now, oh, ah, just, and sort of (Aijmer 2002). Deutschmann (2003) used corpus-linguistic methods to investigate apologies in the British National Corpus. He argued that apologies in British English are routinized to such a degree that searches for elements such as sorry, excuse, or pardon retrieve most of the apologies in the corpus. Stenström et al. (2002) and G. Andersen (2001) provide a detailed pragmatic analysis on the basis of the Corpus of London Teenage Language (COLT).

Corpus pragmatics faces some difficult methodological challenges. While surface forms, such as particular discourse markers or routinized phrases, can relatively easily be retrieved, it is very difficult to retrieve underlying speech functions such as specific speech-act values or expressions of politeness. For some more recent work see, for instance, Adolphs (2008), who investigates a range of utterance functions in large corpora of spoken English, and the papers in the collections of Romero-Trillo (2008), and of Jucker et al. (2009).

It has to be stressed that this brief sketch of a development of different types of data in pragmatic research should not be seen as reflecting a linear development leading from one type of research to the next. What happened was rather that new types of data and new research methods became available and added to the research methods that were already there and thus led to an increasing diversification of pragmatics. In fact, there is no research method and no particular type of data that is constitutive of pragmatics in general. Even the introspective methods that stood at the beginning of the development of pragmatics have not disappeared. In certain branches, such as cognitive pragmatics and in particular Relevance theory (Sperber and Wilson 1986; Blakemore 1992; Carston 2002), introspective data is still the chosen method. While many researchers argue for the superiority of a particular method of investigation, others advocate a more eclectic view that appreciates the relative strengths and weaknesses of research methods in relation to the specific analytical task to be undertaken. See for instance Jucker (2009), who discusses a broad range of research methods that have been applied in the research of speech acts and in particular in the research of compliments and compliment responses.

\subsubsection{From homogeneity to heterogeneity}

A further paradigm shift that had major consequences for the landscape of linguistics was the shift from homogeneity to heterogeneity. Chomskyan linguistics tried to describe a homogeneous system of native speaker competence. Such fields as sociolinguistics and text linguistics that started in the 1970 s focused on the variability of language and its heterogeneity. The paradigm shift can also be discerned in the monumental descriptive grammars of the English language. Quirk et al.'s Grammar of Contemporary English (1972) and their Comprehensive Grammar of the English Language (1985) acknowledge some dialectal and stylistic variation in English but in general they describe the English language as a more or less homogeneous entity. Biber et al. (1999), on the other hand, in their Longman Grammar of Spoken and Written English focus centrally on the differences between spoken and written English and between different genres of written English, such as news language, academic discourse, and the language of fiction. English is no longer seen as a homogeneous entity. The heterogeneity is foregrounded and taken seriously. The early work in pragmatics also depended to a large degree on the (implicit) assumption of a language as a more or less homogeneous entity Pragmaticists were perhaps not particularly quick to pick up the trend set by sociolinguists to focus on variability and heterogeneity in language. The reason for this may be the fact that sociolinguists largely concentrated on 
phonological variation, variation that was taken to imply no difference in the meaning of what was said, i.e. on different ways of saying the same thing Pragmaticists, on the other hand, were explicitly interested in the mean. ings of what was said, i.e. in elements that were more difficult to contrast And in fact, it was in contrastive pragmatics that pragmatic units were first compared in different varieties, or rather - at least initially - in different lan guages. Contrastive pragmatics grew out of a very active research tradition of contrastive linguistics. An early volume was Oleksy (1989), which com bined articles that discuss the possibility of contrasting pragmatic entities e.g. speech acts, across different languages and different cultures. Severa papers deal with compliments and investigate the realization of this partic. ular speech act in different cultures. Krzeszowski (1989), one of the papers in that volume, discusses the problem of contrastive studies from a more theo. retical angle, viz. the choice and the status of a specific tertium comparationis or the notion of equivalence "since only equivalent elements across languages are at all comparable" (Krzeszowski 1989: 59). Some aspect of the construction under investigation has to stay constant across the different contexts in which it is to be compared. Several of the other papers in the same volume focus on praising, complimenting, and responses to compliments and com. pare these speech acts across different cultures and languages, e.g. Polish and English.

A distinction must be made between contrastive and intercultural prag. matics. Contrastive pragmatics sets out to compare interactive patterns in different cultures, while intercultural pragmatics focuses on the interac tions between members of different cultures. In both cases culture is often understood in a very wide sense and can refer to linguistic differences between groups of people, to generational differences, to social differences, or to gender differences. Generalizations across such groups are difficult and tend to lead to stereotyping, but statements about differences between the groups or about interactional problems that occur in conversations between members of different groups depend on generalizations for entire groups.

In fact, earlier work in intercultural pragmatics often set out to identify problem areas in the interaction between members of different cultures and how these could lead to misunderstandings (see, for instance, Scollon and Scollon 2001). In recent years, however, the field has moved on to look "beyond misunderstandings," to use the formulation of the title of a vol. ume edited by Bührig and Ten Thije (2006). The focus has moved away from merely looking at the factors that prevent understanding to a close analysis of the processes that lead to mutual understanding. Moreover, recent work in intercultural pragmatics no longer accepts the essentialist assumptions that speakers belong to or have a particular culture and as such are at the mercy of the peculiarities of this culture. Cultural assumptions are constructions that are jointly created and re-created by large groups of people.
These groups are too large to be "real" groups (i.e. no group member will ever know all the other group members). Therefore, they are best considered as discursive constructions. That means that we do not have culture but that we construct culture discursively. (Piller 2007: 211)

There is also a noticeable body of work on pragmatic differences between different groups of speakers of the same language, most notably on the differences between the genders. The papers in a volume edited by Tannen (1993a) for instance, focus on gender-related patterns in conversational interaction. Holmes (1995) and Mills (2003) investigate the differences in politeness behavor between men and women. ${ }^{3}$ Holmes uses data collected in New Zealand and focuses on the ways in which men and women use hedges and boosters, and how they pay compliments or apologize, while Mills develops a model of the complex relation between gender and politeness in order to challenge the stereotype that women are more polite than men. Beeching (2002) focuses on the same stereotype but she uses French data, and she uses four pragmatic particles, c'est-à-dire (que), enfin, hein, and quoi for her argumentation.

Recently, there has been a growing interest in some of the other dimensions of language-internal variation of pragmatic entities. Schneider and Barron (2008a) have given this field of investigation its own name, "variational pragmatics," which they see as a field at the intersection of pragmatics and dialectology. Schneider and Barron (2008b), in the introduction to their volume, develop a framework for variational pragmatics in which they envisage five types of language variation as possible dimensions of investigation: regional, socio-economic, ethnic, gender, and age variation. The articles in their volume provide case studies of regional variation and contrast the realization of requests in corner-shop transactions in Ecuadorian Andean Spanish and Coastal Spanish (Placencia 2008), for instance, or the realizational patterns of small talk in England, Ireland, and the USA (Schneider 2008).

\subsubsection{From synchrony to diachrony}

The last paradigm shift to be briefly outlined is the shift from a strictly synchronic analysis of language to a dynamic and diachronic analysis. In fact, de Saussure's clear-cut distinction between synchronic and diachronic linguistics has given way to an understanding of language as a dynamic system in which older and newer forms co-exist and any description of language has to take its history seriously. As a result historical linguistics has grown in importance, and at the same time it has extended its interests from the confines of the core areas of linguistic investigation, such as phonology, morphology, syntax, and semantics, to wider investigations of the history of the use of language.

The growing interest in language history coincided with the growing interest in the compilation of computerized corpora. This combination led to the Helsinki Corpus, which combines a large selection of historical English texts 
covering the period from about 750 to 1700 and a broad range of different text genres (see for instance the papers in Rissanen, Kytö and Palander-Collin 1993). This general-purpose diachronic corpus was soon followed by more specialized diachronic corpora, for instance the Corpus of Early English Cor. respondence (1403-1800) or the Corpus of Early English Medical Writing (1375-1800). The availability of such corpora, at least for the English lan. guage, was the basis for an unprecedented proliferation of work in historical linguistics. Much of the work was sociolinguistically inspired, e.g. Nevalainen and Raumolin-Brunberg (2003), Taavitsainen and Pahta (2004), Nevala (2004), and Nurmi and Palander-Collin (2009).

At the same time some pragmaticists started to turn their attention to a larger range of empirical data. They insisted no longer on the native speaker intuitions of language philosophers or on the faithful transcrip. tions of aurally recorded conversational data. Instead they started to accept various forms of written language as legitimate and useful data for investigation. Thus, the formation of historical pragmatics as a new branch of pragmatics in the 1990 s can be seen as the direct result both of the paradigm shifts in linguistics in general and the shifts within pragmatics. Jucker 1995 was an early volume that gave the new field a focus. Since then historical pragmatics has established itself with its own journal (Joumal of Historical Pragmatics), a large range of monographs, collected volumes, and recently a substantial handbook (Jucker and Taavitsainen 2010).

In the meantime, historical pragmatics has established itself as a vigor ous and lively branch of pragmatic research, which sees itself as a field of enquiry that investigates patterns of language use in earlier periods, the diachronic development of such usage patterns, and pragmatic explanations for language change in general (see Taavitsainen and Fitzmaurice 2007 and Taavitsainen and Jucker 2010 for recent overviews). ${ }^{4}$

Patterns of language use in earlier periods have often been studied on the basis of fictional data, for instance the writings of Geoffrey Chatcer (see Pakkala-Weckström 2010 for an overview) or of William Shakespeare (see Busse and Busse 2010 for an overview). Such work often looks at the use of pronominal and nominal terms of address, at other features of politeness, at the use of specific speech acts or interjections. For historical pragmaticists, such data are not imperfect renderings of actual lan guage use but a type of data that warrants a careful pragmatic analy sis on its own terms. Courtroom data and personal correspondence have also regularly been used for pragmatic analyses. Culpeper and Kytö (2010) offer a recent account of historical conversational data. Their studies are based on their own Corpus of English Dialogues 1560-1760, which comprises data from trial proceedings, witness depositions, plays, fiction, and didactic works.

Historical pragmatics has developed quite considerably from its begin nings in the 1990s and from more incidental earlier work; and this history reflects developments and paradigm shifts in linguistics in general.

\subsection{Pragmatics of the future}

Pragmatic research in the first decade of the twenty-first century has been characterized by an unprecedented diversification of subfields of pragmatchar This is particularly true for the Continental European tradition of pragmatics, and as such it was perhaps inevitable. If pragmatics is seen as a prspective, as a particular way of doing linguistics in general, it is not surperspective, as a particular way of doing linguistics in general, it is not surprising that it starts to colonize more and more of what used to be subfields of linguistics. Research interests and research methods of earlier subfields flinguistics were extended to encompass a pragmatic perspective as well. and at the same time, pragmatics extended its scope to encompass research And at the same time, pragmatics extended its scope to encompass research questions and research methods that had earlier been used by other fields of linguistics. In many cases relevant pragmatic work in these fields started in the 1990 s or even 1980 s, but it was often only in the twenty-first century the fields constituted themselves in a more recognizable and coherthat way, as for instance in the case of variational pragmatics or corpus praginatics.

The paradigm shifts that affected linguistics in general to some exten The paradigm shif of pragmatics and to some extent shaped it in specific constituted the field of pragmatics and to some extent shaped it in specific ways. In the previous section I have outlined in separate listorits appear to be the most important of these shifts. In reality, these shifts overlap and converge in the trends that are discernible. To take just one example, historical pragmatics clearly depends on the shift from a study of native speaker competence to a study of language use, as there are no historical speakers whose native language competence could be described. This also necessitates the use of empirical methods of investigation and within the necessitates the use of empirical methods on focus much more on the heterogeneity and variability of the data than focus much inore from synchrony to diachrony is just on the homogeneity. And the shift from synchrony to diachrony is just as constitutive of historical pragmatics as the shift from

language competence to a description of usage patterns. But what will the future development of pragmatics look like? What might a gaze into the crystal ball reveal about the praginatics of the futu develop difficult to extrapolate from current developments into how it might develop in the future. However, a few things can be predicted quite confidently. Pragmatics is a very strong field of scientific enquiry, and as such it will continue to grow. At the moment, the distinction between the narrower conceptualization of Anglo-American pragmatics and the broader, socially and culturally informed variety of Continental European pragmatics is still and culturally informed variety of Continental Eur some thirty years ago by Levinson (1983: 2). It does not seem likely, therefore, that this difference will be given up in the foreseeable future.

Over the last two decades, personal computers, the internet, and the mobile phone have radically changed the way many people communicate with each 
other. These technical innovations have added new forms of spoken and writ ten communication from email messages, short text messages, and writte chat to skype conversations, tweets, weblogs, and various forms of comm nication in virtual worlds and internet-based social networks. In recent years the flood of pragmatic analyses of these new forms of communication has grown steadily (see, for instance, Crystal 2001, 2008; Barnes 2003; Loche 2006; Heyd 2008). It is to be expected that the pragmatics of compute mediated communication has an enormous potential for future growth

There is very likely to be a continuing and perhaps accelerating divers fication of approaches within pragmatics. Cooperation between traditiona fields of linguistics and pragmatics will continue. Historical pragmatics which combines historical linguistics and pragmatics, and variational prag. matics, which combines dialectology and pragmatics, have been mentioned above. Both of them are very promising fields with a vast range of research opportunities. Corpus pragmatics is another such field that has only recently constituted itself and that has enriched pragmatics with a new set of research tools that offer exciting perspectives for exploring new and as yet uncharted pragmatic territory.

\section{Semantics without pragmatics?}

Emma Borg

Philosophers of language (following the seminal work of Paul Grice) often distinguish two types of linguistic content: literal or semantic content (usually discussed in the context of sentences) and pragmatic content or speaker meaning (usually discussed in the context of utterances). For instance, imagine I come to tea at your house and, on entering the kitchen, utter the following sentence:

(1) The cake on the table looks delicious.

Traditionally, since (1) is a well-formed sentence of a natural language, many theorists have been inclined to think that there is a proposition expressed by the sentence which gives its literal meaning. So, at least at a first approximation, (1) might be held to literally express the proposition that

(2) the cake on the table looks delicious.

However it also seems that, by uttering this sentence in this specific context, I may well succeed in conveying an alternative or additional proposition (or propositions). So, for instance, in this situation I may succeed in conveying a further proposition like:

(3) I would like to have a slice of that cake.

It might initially be tempting here to think that what we have is one kind of content - the literal meaning in (2) - which is entirely independent of a context of utterance and another - the pragmatic speaker meaning - which is entirely dependent on the context of utterance. If this were right, we could construe semantic content as context-invariant content and speaker meaning as that which covaries with changes in the context of utterance, and we could expect a semantic theory to be freed from any appeal to pragmatics.

Holding that semantic content is context-invariant might seem to be worthwhile for a number of reasons. First, there might be negative reasons concerning the complex, holistic and perhaps rather nebulous nature 